\title{
Pengaruh Stimulasi Al-Qur'an Terhadap Glasgow Coma Scale Pasien Dengan Penurunan Kesadaran di Ruang ICU
}

\author{
Zuhriana K. Yusuf, Asriyanto Rahman \\ Fakultas Olahraga dan Kesehatan Universitas Negeri Gorontalo \\ E-mail: nunu.fkung@ung.ac.id
}

\begin{abstract}
ABSTRAK
Pasien dengan penurunan kesadaran masih tinggi angka kejadiannya. Salah satu terapi untuk menangani pasien dengan penurunan kesadaran adalah dengan pemberian stimulasi Al-Qur'an. Tujuan penelitian mengetahui pengaruh stimulasi Al-Qur'an terhadap Glasgow Coma Scale pasien dengan penurunan kesadaran diruang Intensive Care Unit (ICU). Jenis penelitian Pre Experiment dengan one grup pre-post test design. Populasi adalah pasien dengan penurunan kesadaran sebanyak 14 pasien. Sampel berjumlah 10 pasien dengan teknik non probability sampling jenis accidental sampling. Data dikumpul melalui observasi, pengukuran Glasgow Coma Scale sebelum dan sesudah intervensi. Dianalisis dengan uji $\mathrm{T}$ berpasangan. Hasil penelitian menunjukkan terdapat peningkatan nilai Glasgow Coma Scale antara sebelum dan setelah pemberian stimulasi Al-Qur'an dengan hasil uji komputerisasi T Berpasangan didapatkan nilai $\mathrm{P}$ value $=0,003$ yang lebih kecil dari $\alpha=0,05$. Kesimpulan dari penelitian ini terdapat pengaruh stimulasi Al-Qur'an terhadap Glasgow Coma Scale pasien dengan penurunan kesadaran di ruang Intensive Care Unit (ICU).
\end{abstract}

Kata kunci: Stimulasi Al-Qur'an, Glasgow Coma Scale, Kesadaran

\begin{abstract}
Patients with decreased awareness still have a high incidence. One of the therapies to restore patients with decreased awareness is to provide Qur'anic stimulation. The aim of the study was to determine the effect of Qur'anic stimulation on GCS patients in ICU. Type of research is pre experiment with one group pre-post test design. The sample amounted to 10 patients with accidental sampling. The results showed an increase in GCS value (p-value $0.003<$ alfa 0.05). The conclusion of this study is there is an influence of Qur'anic stimulation on GCS patien in ICU.
\end{abstract}

Keywords: Qur'anic stimulation, GCS, awareness

\section{PENDAHULUAN}

Intensive Care Unit (ICU) merupakan suatu bagian dari rumah sakit yang mandiri dengan staf khusus dan perlengkapan yang khusus. Pasien yang layak dirawat di ruang ini yaitu pasien yang memerlukan intervensi medis segera, pemantauan kontinyu serta pengelolaan fungsi sistem organ tubuh secara terkoordinasi oleh tim intensive care. Hal tersebut dilakukan supaya pasien terhindar dari dekompensasi fisiologis serta dapat dilakukan pengawasan yang konstan, terus menerus dan pemberian terapi titrasi dengan tepat (Kemenkes RI,2012).
Menurut Patient and Family Support Committee of the Society of Critical Care Medicine (2002) dalam Berger \& Pichard (2012) bahwa permasalahan umum yang sering terjadi pada pasien kritis yang dirawat di ruang rawat intensif antara lain gangguan neurologis, perdarahan, ketidakstabilan hemodinamik dan cairan elektrolit, syok, gagal napas akut dan kronik, infeksi nosokomial, gagal ginjal, nyeri dada, sepsis serta Multiple Organ Dysfunction Syndrome (MODS). Diperkirakan bahwa sekitar 13 sampai dengan 20 juta orang pertahun membutuhkan dukungan kehidupan di unit perawatan intensif di 
seluruh dunia (Adhikari, Fowler, Bhagwanjee, \& Rubenfeld, 2010).

Menurut World Health

Organization (WHO), pasien kritis di ICU prevalensinya meningkat setiap tahunnya. Tercatat 9.8-24.6\% pasien sakit kritis dan dirawat di ICU per 100.000 penduduk, serta kematian akibat penyakit kritis hingga kronik di dunia meningkat sebanyak 1,1 -7,4 juta orang (WHO, 2016) Di 16 ICU Rumah Sakit di negaranegara Asia termasuk Indonesia terdapat 1285 pasien sepsis yang menggunakan ventilator dengan ratarata

lama penggunaan ventilator 3-10 hari dan 575 pasien diantaranya meninggal dunia (WHO, 2016). Di Rumah Sakit Umum Daerah Prof. Dr.Hi. Aloei Saboe itu sendiri, berdasarkan pengambilan data awal dari medical record, dalam data kurun waktu 6 bulan terakhir (data Agustus 2017-Januari 2018) diperoleh jumlah pasien kritis di ruang ICU ada sebanyak 383 orang dengan presentasi penurunan kesadaran 97,8\% (Medical Record,2018).

Penurunan kesadaran memerlukan perawatan dan penanganan segera untuk mengurangi kesakitan dan mencegah kematian. Oleh karena itu peran perawat sangat penting dalam melakukan asuhan keperawatan untuk meningkatkan status kesadaran dan meminimalisir kecacatan. Berbagai upaya asuhan keperawatan yang telah dikembangkan untuk membantu meningkatkan kesadaran pasien, antara lain: oksigenasi, pengaturan posisi, dan stimulasi suara dan sentuhan (Mutaqqin, 2008). Salah satu jenis intervensi yang dilakukan dalam stimulasi suara yakni pemberian stimulasi Al-Qur'an.
Berdasarkan wawancara awal penulis dengan kepala ruangan ICU, penggunaan stimulasi Al-Qur'an ini sudah pernah dilakukan oleh beberapa perawat di ruangan, dalam hal ini perawat hanya sekedar menyarankan keluarga untuk memperdengarkan lantunan ayat suci AlQur'an kepada pasien selama berada keadaan kondisi kritis. Namun dalam pemberian tindakan ini perawat tidak memperhatikan intensitas dan tidak menilai pengaruhnya terhadap status kesadaran. Beberapa penelitian pun pernah menggunakan stimulasi Al-Qur'an ini namun tidak memperhatikan status kesadaran dan lebih ke stabilisasi hemodinamik pasien.

\section{METODE}

Penelitian ini dilaksanakan di ruang Intensive Care Unit (ICU) Rumah Sakit Aloei Saboe Kota Gorontalo sejak tanggal 01 Juni sampai dengan tanggal 13 Juni 2018. Desain penelitian adalah penelitian Pra Experiment dengan desain One group pra-post test, Populasi penelitian ini adalah klien dengan penurunan kesadaran di Ruang Intensive Care Unit (ICU) Rumah Sakit Umum Daerah Prof. Dr. Hi. Aloei Saboe Kota Gorontalo yang berjumlah 14 orang (Medical Record,2018) dan penarikan sampel sebanyak 10 responden secara Accidental Sampling. Analisa data dalam penelitian ini menggunakan statistik Uji T Berpasangan jika data berdistribusi normal. 


\section{HASIL}

Tabel 1. Distribusi responden

\begin{tabular}{llcc}
\hline No & Data Demografi & $\begin{array}{c}\text { Jumlah } \\
\text { (n) }\end{array}$ & Frekuensi (\%) \\
& & 5 & \\
\hline 1 & Jenis Kelamin & 50,0 \\
& Laki-laki & 5 & 50,0 \\
& Perempuan & & \\
& Rentang Umur & 1 & 10,0 \\
& 36-45 th & 4 & 40,0 \\
& 46-55 th & 3 & 30,0 \\
& $56-65$ th & 2 & 20,0 \\
\hline
\end{tabular}

Tabel 2. Distribusi Responden Berdasarkan Diagnosa Medis

\begin{tabular}{llcccc}
\hline No & Diagnosa Medis & $\begin{array}{c}\text { Diagnosis } \\
\text { Primer }\end{array}$ & $\begin{array}{c}\text { frekuensi } \\
(\%)\end{array}$ & $\begin{array}{c}\text { Diagnosis } \\
\text { Second }\end{array}$ & $\begin{array}{c}\text { Frekuensi } \\
(\%)\end{array}$ \\
\hline 1 & Gagal Nafas & 8 & 80,0 & 0 & 0 \\
2 & COB & 0 & 0 & 1 & 10,0 \\
3 & Stroke & 1 & 10,0 & 2 & 20,0 \\
4 & TB Paru & 0 & 0 & 2 & 20,0 \\
5 & Post & 0 & 0 & 3 & 30,0 \\
6 & Craniotomy & 1 & 10,0 & 0 & 0 \\
7 & Pneumonia & 0 & 0 & 1 & 10,0 \\
8 & CHF & 0 & 0 & 1 & 10,0 \\
& Total & 10 & 100 & 10 & 100 \\
\hline
\end{tabular}

Tabel 3. Distribusi GCS Responden Sebelum dan Sesudah Diberikan Perlakuan Stimulasi Al-Qur'an (Pretest dan Posttest)

\begin{tabular}{|c|c|c|c|}
\hline \multirow[t]{2}{*}{ No } & \multirow[t]{2}{*}{ Nilai GCS } & Pre Test & Post Test \\
\hline & & Jumlah (n) & Jumlah (n) \\
\hline 1 & $10-11$ & 0 & 2 \\
\hline 2 & $7-9$ & 4 & 3 \\
\hline 3 & $5-6$ & 2 & 4 \\
\hline 4 & 4 & 3 & 0 \\
\hline 5 & 3 & 1 & 1 \\
\hline
\end{tabular}

Total

10

10

Tabel 4. Pengaruh Stimulasi Al-Qur'an terhadap Glasgow Coma Scale Pasien dengan Penurunan Kesadaran di Ruang ICU

\begin{tabular}{|c|c|c|c|c|c|c|}
\hline \multirow[t]{2}{*}{ Responden } & \multirow{2}{*}{$\begin{array}{l}\text { GCS } \\
\text { Sebelum }\end{array}$} & \multirow{2}{*}{$\begin{array}{l}\text { GCS } \\
\text { Sesudah }\end{array}$} & \multirow[t]{2}{*}{ Keterangan } & \multicolumn{2}{|l|}{ CI } & \multirow[t]{2}{*}{$p$ Value } \\
\hline & & & & Lower & Upper & \\
\hline 1 & 4 & 5 & Meningkat & $-2,169$ & $-0,631$ & 0,003 \\
\hline 2 & 8 & 9 & Meningkat & & & \\
\hline 3 & 5 & 7 & Meningkat & & & \\
\hline 4 & 4 & 5 & Meningkat & & & \\
\hline 5 & 7 & 11 & Meningkat & & & \\
\hline 6 & 3 & 3 & Tetap & & & \\
\hline 7 & 7 & 9 & Meningkat & & & \\
\hline 8 & 5 & 6 & Meningkat & & & \\
\hline 9 & 4 & 5 & Meningkat & & & \\
\hline 10 & 9 & 10 & Meningkat & & & \\
\hline
\end{tabular}




\section{PEMBAHASAN}

GCS Sebelum Pemberian Stimulasi AlQur'an

Berdasarkan hasil observasi awal sebelum perlakuan Stimulasi Al-Qur'an memberi gambaran bahwa dari 10 responden, responden yang masuk dalam GCS 7-9 saat pre test sebanyak 4 responden, responden dengan GCS 5-6 sebanyak 2 responden, responden dengan GCS 4 sebanyak 3 responden dan responden dengan GCS 3 sebanyak 1 responden.

Pasien yang dirawat di ruangan ICU ini rata-rata mengalami penurunan kesadaran dengan GCS $<10$ dengan tingkat kesadaran somnolent (GCS 9-7) sebanyak 4 responden, Semi koma (GCS 4) sebanyak 3 responden, Stupor (GCS 65) sebanyak responden, dan koma (GCS 3) sebanyak 1 responden. Hal ini diakibatkan oleh ketidak seimbangan perfusi dan ventilasi sehingga transfer oksigen tidak adekuat keseluruh tubuh hingga ke otak dan mempengaruhi tingkat kesadaran (Silbernagel, Stefan, \&Florian, 2007 dalam Tampoy, 2017).

Penurunan tingkat kesadaran ini dipengaruhi oleh beberapa factor seperti sirkulasi yang tidak adekuat sehingga transport oksigen ke jaringan tidak adekuat dan menimbulkan hipoksia otak, gangguan pada otak akibat trauma dan nontrauma, sepsis dan intoksikasi, gangguan pada metabolic tubuh, ketidakseimbangan elektrolit tubuh yang mengganggu kerja organ dan kerja listrik otak (Harsono, 2008 dalam Hasan 2017).

Asumsi peneliti, faktor pencetus diatas berhubungan dengan diagnose klinis yang ditemukan pada ke-10 pasien yang dijadikan sebagai responden. Gangguan otak akibat penyakit trauma maupun penyakit non trauma yang ditemukan pada klien akan mempengaruhi aliran darah dan suplay oksigen ke otak menjadi tidak adekuat sehingga berdampak pada kesadaran seseorang.

\section{GCS Setelah Pemberian Stimulasi Al-} Qur'an

Setelah diberikan perlakuan stimulasi Al-Qur'an terjadi perubahan GCS dimana pada post test yang didapatkan setelah perlakuan ke-6, dari 10 responden 9 diantaranya terjadi perubahan pada tingkat kesadaran. Pada penelitian ini, rata-rata setiap responden mengalami peningkatan nilai GCS secara Motorik. Setelah diberkan intervensi berupa Stimulasi Al-Qur'an sebanyak 6 kali perlakuan, ketika dilakukan penilaian tingkat kesadaran oleh perawat, saat diberikan rangsangan nyeri $\mathrm{di}$ area Procesus xypoideus perlahan-lahan skor Motorik meningkat 1-2 angka dimana semula responden hanya mampu melakukan gerakan fleksi maupun ekstensi abnormal, responden mulai berusaha untuk menjangkau area nyeri yang diberikan meskipun tidak mencapai sasaran yang diberikan rangsangan nyeri.

Tidak hanya pada Motorik saja, adapun responden yang mengalami peningkatan pada Eye dimana semula mata hanya merespon terhadap nyeri, responden mulai berusaha untuk melakukan bukaan mata ketika dipanggil namanya atau ketika diberi perintah untuk membuka mata walau tidak terbuka sepenuhnya. Salah satu responden pada penelitian ini contohnya mengalami peningkatan nilai GCS 4 angka dimana penambahan skor 
GCS ini terdapat pada motorik dan eye dari responden tersebut.

Hasil penelitian di atas sejalan dengan penelitian yang dilakukan oleh Arif Setyo Upoyo (2012) dimana setelah dilakukan pemberian stimulasi Al-Qur'an hasil yang didapatkan adalah terdapat perbedaan nilai GCS yang bermakna sebelum dan setelah intervensi $(p=0,034)$. Terdapat perbedaan peningkatan nilai GCS yang bermakna antara kelompok intervensi dan kelompok kontrol $(\mathrm{p}=0.013)$. Stimulasi dengan memperdengarkan murotal Al Quran mempunyai pengaruh positif dalam meningkatkan kesadaran pasien stroke iskemik, sehingga direkomendasikan pada pasien stroke iskemik yang mengalami penurunan kesadaran.

Pada hasil penelitian yang dilakukan, peneliti menemukan 1 responden tidak mengalami peningkatan derajat kesadaran. Berdasarkan distribusi responden, diperoleh bahwa responden yang tidak mengalami kenaikan GCS adalah pasien dengan GCS 3 dimana GCS 3 ini tergolong dalam Cedera Otak Berat. Pada saat pengukuran awal sebelum dilakukan intervensi pasien menunjukkan tanda dan gejala Mati Batang Otak (MBO). Hal ini menjadi kemungkinan faktor yang dapat mempengaruhi tidak terjadinya peningkatan nilai GCS pada responden tersebut.

Berdasarkan teori yang dikemukakan oleh Hudak \& Gallo 2002 (dalam Lumbantobing, 2015), mengatakan bahwa cedera kepala sedang memiliki prognosis lebih baik dari pada cedera kepala berat. Hal ini dikuatkan oleh penelitian yang dilakukan oleh Abdul 2006, mengemukakan hasil penelitiannya dimana pada cedera kepala berat lebih sering mengalami hipoksia sistemik yang akan memperburuk prognosa, karena pada cedera kepala dengan gangguan fungsi otak dimana $\mathrm{O} 2$ kurang dari 2,5 cc per 100 gram otak permenit akan mulai terjadi gangguan mental dan umumnya bila kurang dari $2 \mathrm{cc}$ per 100 gram otak permenit dapat mengakibatkan koma pada pasien sehingga pada cedera kepala berat membutuhkan waktu yang lebih lama dalam peningkatan kesadaran/nilai GCS (Lumbantobing, 2015).

\section{Analisis Pengaruh Stimulasi Al-Qur'an terhadap GCS}

Berdasarkan hasil komputerisasi melalui uji $\mathrm{T}$ Berpasangan didapatkan terdapat pengaruh stimulasi Al-Qur'an pengaruh stimulasi Al-Qur'an terhadap perubahan GCS pada pasien dengan penurunan kesadaran di Intensive Care Unit.

Fungsi pemberian terapi pada pasien dengan penurunan kesadaran adalah sebagai pemberi neuro protektor. Tujuan pemberian neuro protektor adalah menyelematkan jaringan yang terkena iskemia,membatasi area yang infark agar tidak meluas, memperlama time window, dan meminimalisir cedera reperfusi. Efek neuroprotektif lain dari stimulasi sensori adalah penghambatan pengeluaran glutamate (Faradina, 2017).

Asumsi peneliti, dengan pemberian Stimulasi Al-Qur'an ini tidak hanya sebagai bentuk dukungan psikologi dan bernilai spiritual, namun juga berperan sebagai neuroprotektif otak melalui stimulus auditori. Oleh karena itu stimulasi sensori dalam hal ini stimulasi Al-

Qur'an dapat dijadikan sebagai salah satu alternatif intervensi keperawatan dalam 
upaya meningkatkan proses pemulihan pasien dengan penurunan kesadaran yang ditandai dengan kenaikan nilai GCS.

\section{SIMPULAN}

Nilai Glasgow Coma Scale setelah diberikan perlakuan stiimulasi Al-Qur'an terjadi perubahan Glasgow Coma Scale dimana pada post test terjadi perubahan pada tingkat kesadaran, dengan hasil responden dengan GCS 10-11 sebanyak 2 responden $(20,0 \%)$, GCS 7-9 sebanyak 3 responden (30,0\%), dan GCS 5-6 sebanyak 4 responden $(40,0 \%)$, Sedangkan 1 responden $(10,0 \%)$ tidak mengalami perubahan tingkat kesadaran yakni tetap pada GCS 3. Terdapat pengaruh stimulasi Al-Qur'an terhadap Glasgow Coma Scale pada pasien dengan penurunan kesadaran di ruang ICU, dimana berdasarkan hasil komputerisasi melalui uji $\mathrm{T}$ Berpasangan didapatkan nilai $\mathrm{P}$ value $=0,003$ yang lebih kecil dari $\alpha=0,05$.

\section{DAFTAR PUSTAKA}

Adhikari, N. K., Fowler, R.

A.,Bhagwanjee, S., \& Rubenfeld,G.

D. (2010). Critical Care And The Global Burden Of Critical Illness In Adults. The Lancets.1339-1346.

Retrieved Juni 10, 2017, fromhttp://doi.org/10.1016/ S01406736(10)60446-1

Berger, M., \& Richard, C. (2012). Best

Timing for Energy Provision during Critical Illness. Berlin: SpringerVerlag Berlin Heidelberg.

Faradina, A. (2017). Pengaruh Terapi Relaksasi Audio : Murotal Al-Qur'an terhadap Perubahan Tingkat Stres pada Pasien di Ruang ICU RS PKU Muhammadiyah Gombong. Skripsi.
Hasan, F. (2017). Pengaruh Mobilisasi Progresif Level I terhadap Perubahan Glasgow Coma Scale (GCS) pada Pasien dengan Penurunan Kesadaran di Ruang ICU RSUD Prof. Dr. H. Aloei Saboe Kota Gorontalo. Mini Riset.Gorontalo: Mini Riset PSIK UNG

Hospital Episode Statistics Analysis,

Health and Social Care Information

Centre.(2014). Hospital Episode

Statistic: Admitted Patient Care,

England - 2014-15 . UK: Health and

Social Care Information Centre.

Kemenkes RI. (2012). Survei Demografi dan Kesehatan Indonesia. Jakarta: Kemenkes RI.

Lumbantobing. (2015). Pengaruh

Stimulasi Sensori terhadap Nilai Glasgow Coma Scale pada Pasien Cedera Kepala di Ruang Neurosurgical Critical Care Unit RSUP Dr.

Hasan Sadikin Bandung. Jurnal Ilmu Keperawatan. Volume III, No. 2, 105111.

Medical Record. (2018). Data Medical Record Pasien Kritis ICU RSAS. Gorontalo: RSAS.

Mutaqqin, A. (2008). Asuhan Klien dengan Gangguan Sistem Persyarafan. Jakarta: Salemba Medika.

Purnawan, I. (2012). Pengaruh Stimulasi Murottal Al-Quran. Naskah Publikasi Tesis.

Tampoy, Y. M. (2017). Pengaruh Terapi Murottal terhadap Tekanan Darah padaPasien yang

Mengalami Penurunan Kesadaran di Ruang ICU RSUD Prof. Dr. H. Aloei Saboe Kota Gorontalo. Mini Riset. Gorontalo: Mini Riset PSIK UNG.

Upoyo, A. S. (2012). Pengaruh Stimulasi Murotal Al Quran Terhadap Nilai Glasgow Coma 
Scale Pada Pasien Stroke Iskemik Di

Rsud Dr. R. Goeteng Aroenadibrata

Purbalingga. Naskah Publikasi Tesis.

World Health Organization. (2016). World

Health Statistic 2015. USA: WHO 